\title{
Crise reputacional e comunicação de marca: a estratégia da Odebrecht para"lavar" a sua imagem
}

\author{
Reputational crisis and brand communication: Odebrecht's strategy to \\ "wash" its image
}

\author{
Wilson da Costa Bueno \\ Universidade Metodista de São Paulo \\ <wilson@comtexto.com.br>
}

\author{
Como citar este artigo (How to cite this article): \\ BUENO, Wilson da Costa. Crise reputacional e comunicação de marca: a estratégia da Odebrecht para "lavar" a \\ sua imagem. Revista Famecos, Porto Alegre, v. 25, n. 2, p. 1-18, maio, junho, julho e agosto de 2018: ID28734. \\ DOI: http://dx.doi.org/10.15448/1980-3729.2018.2.28734.
}

\section{RESUMO}

Muitas empresas têm desenvolvido esforço permanente no sentido de dar visibilidade às suas marcas, valendo-se de estratégias ou técnicas que afrontam a ética e a transparência. A comunicação de marca, nesse caso, assume um tom ao mesmo tempo grandiloquente, de autoelogio, e quase sempre falso, que subestima a capacidade dos cidadãos de identificarem as intenções ocultas em seu discurso. O artigo discute algumas estratégias contemporâneas da comunicação de marca, com foco nas ações desenvolvidas pelo grupo Odebrecht para "lavar" a sua marca e, desta forma, resgatar a sua reputação degradada por posturas não éticas reveladas pela Operação Lava-Jato. É possível destacar, entre estas ações, o uso de vídeos institucionais, do marketing de conteúdo em veículos da grande imprensa e a mudança dos nomes e logotipos das empresas do Grupo.

Palavras-chave: Comunicação de marca. Marketing de conteúdo. Brand content.

\section{ABSTRACT}

Many companies have made a permanent effort to give visibility to their brands, using strategies or techniques that face ethics and transparency. Brand communication, in this case, assumes a tone that is both grandiloquent, self-effacing, and almost always false, which underestimates citizens' ability to identify the hidden intentions in their speech. The article discusses some contemporary strategies of brand communication, focusing on the action developed by the Odebrecht group to "wash" their brand and, therefore, their reputation degraded by unethical positions revealed by Operation LavaJato. It is possible to highlight, among these actions, the use of institutional videos, the marketing of content in vehicles of the main press and the change of the names and logos of the Group companies.

Keywords: Brand communication. Content marketing. Brand content. 


\section{Introdução}

A marca representa, assim como a imagem, a reputação, o capital humano e a capacitação para inovar, um dos ativos intangíveis considerados estratégicos para as organizações modernas.

A literatura sobre marcas, gestão de marcas e valor da marca publicada no Brasil é generosa e merecem ser citadas como referência obras de autores que estudam ou prestam consultorias nesse campo, como Troiano (2009), Serralvo (2008), Tomiya (2010), Tybout; Calkins (2006) e Freitas; Neto (2015), dentre dezenas de outras.

Apesar disso, a bibliografia sobre comunicação e gestão de marcas ainda se caracteriza por algumas lacunas, como, por exemplo, não a contemplar a partir da comunicação organizacional, em seu sentido mais abrangente. De maneira geral, o foco da literatura a respeito deste tema se mantém, prioritariamente, vinculado a uma proposta estritamente mercadológica, com atenção às relações de consumo, ou ainda às técnicas ou metodologias que favorecem a mensuração do valor da marca.

É razoável admitir que existem basicamente dois motivos para que isso ocorra. Em primeiro lugar, as marcas têm frequentado, há algum tempo, e com bastante desenvoltura, a bibliografia específica de propaganda e marketing, sendo objeto de ações e estratégias que se reportam a estas atividades profissionais. Em segundo lugar, não há dúvida de que, com o crescente volume de fusões e aquisições de empresas, a mensuração do valor da marca ganhou atenção especial do ponto de vista contábil e financeiro, representando fator fundamental para subsidiaras transações decompraevendaentreascorporações.

A ampliação do conceito de marca (hoje nos referimos à marca corporativa e mesmo à marca pessoal, além da de produtos e serviços) e a perspectiva acertada de contemplá-la como um ativo intangível estratégico têm reformulado drasticamente o próprio processo de comunicação da marca, inserindo-o, umbilicalmente, na comunicação organizacional, o que possibilita a articulação necessária entre as dimensões institucional e mercadológica. A literatura recente desta área, e especialmente os eventos em comunicação organizacional, evidenciam esta nova realidade, indicando a presença expressiva das marcas como objeto de estudo e pesquisa.

O processo de gestão das marcas busca, avidamente, conferir-lhes credibilidade e prestígio, empenhando-se para posicioná-las a partir de novos atributos valorizados na contemporaneidade, como a sustentabilidade, a inovação, a qualidade de vida e a ética empresarial. Este esforço está respaldado na tese de que as marcas que exibem esse perfil evocam maior fidelidade dos 
consumidores, são menos vulneráveis às crises e permitem a obtenção de margens de lucro maiores.

\section{A personalidade e a imagem da marca}

O processo de comunicação da marca abrange um conjunto significativo de ações, estratégias e canais de relacionamento voltados para a construção de sua personalidade, a consolidação de uma imagem positiva e o incremento do seu valor e da sua força. Ter presente a diferença entre esses conceitos (personalidade, imagem, valor e força da marca não podem ser vistos como sinônimos) é fundamental porque cada um deles define processos comunicacionais singulares e que devem ser desencadeados em tempo e formato específicos.

A personalidade da marca pode ser entendida como um conjunto de características que a definem e que podem estar associadas, por exemplo, a gênero, à idade, a uma determinada classe socioeconômica ou mesmo a um determinado estilo de vida ou cultura. Assim, podemos falar em marcas femininas, marcas jovens, marcas de elite ou de luxo e marcas conservadoras ou tradicionais.

A personalidade da marca é, frequentemente, influenciada pela categoria do produto ou serviço à qual ela está associada e, no caso de marcas corporativas, a sua personalidade decorre, certamente, do setor ao qual ela se filia. Os públicos de uma organização e a sociedade como um todo acumulam uma série de percepções e pré-conceitos (e mesmo preconceitos) em relação a determinados setores empresariais e às companhias que os integram. Podemos dizer que o "core business da empresa", que explicita a sua área de atuação, de alguma forma adere (em alguns casos, contamina) à sua marca (corporativa e de produtos), criando leituras padronizadas por parte dos stakeholders e da opinião pública de maneira geral. É importante admitir que a mudança de personalidade de uma marca constitui um processo de difícil gestão porque, em geral, sobretudo para as marcas que estão há longo tempo no mercado ou detém consumidores fiéis (os fãs da marca), a incorporação de um novo "ethos" não é tarefa nem fácil nem rápida. $E$, num mundo em movimento, que molda novos perfis de públicos, novos desejos de consumo, as marcas são pressionadas permanentemente a se modificarem.

Pode-se definir a imagem da marca (seja ela corporativa, seja ela de produtos) como a representação mental de uma organização ou empresa (ou de seus produtos) construída por um indivíduo ou grupo a partir de percepções e experiências concretas, informações e influências recebidas de terceiros ou da mídia. 
Essa definição acarreta, de imediato, alguns desdobramentos, porque uma determinada empresa (Microsoft, Natura, Nestlé etc.) pode fabricar vários produtos ou prestar serviços em diversas áreas. Como os públicos podem ser distintos para cada um deles, é razoável admitir que a marca corporativa e a dos seus produtos ou serviços individuais podem não ter imagens coincidentes.

Além disso, poruma decisão da empresa (sua estratégia de posicionamento no mercado), a marca corporativa não está associada obrigatoriamente à marca corporativa. Algumas corporações (a Unilever, a P\& G são exemplos emblemáticos) optam por ter marcas de produtos que não se reportam à marca corporativa e que parecem ter uma vida independente, de tal modo que parcela significativa dos consumidores, dos stakeholders e da opinião pública de maneira geral não reconhece os vínculos que eles mantêm entre si.

\section{A comunicação de marca}

Tradicionalmente, a comunicação de marca sempre esteve associada a estratégias inseridas no campo da propaganda e marketing, sobretudo pela utilização de anúncios impressos ou audiovisuais ou mesmo de campanhas publicitárias, mas, na sociedade digital, tem evoluído para uma proposta mais abrangente, multiplataforma, integrando e/ou articulando diversos canais, com o objetivo de dar maior visibilidade a produtos e serviços e favorecer a sua comercialização e consumo.

A comunicação digital da marca consolidou as chamadas comunidades de marca (Freitas; Almeida, 2017), buscou trazer novos influenciadores para o incremento do processo de divulgação das marcas, como blogueiros e produtores de vídeos, bem como estimulou a incorporação, que chega em inúmeros casos a ser abusiva, de celebridades (artistas, esportistas etc.) para a promoção de produtos e serviços.

Pablo Viana (2016) resgata de forma ampla a evolução da comunicação de marca, buscando em particular definir os conceitos utilizados para identificar o processo de integração do discurso publicitário aos conteúdos, fixando-se sobretudo nos de Product Placement, Branded Content e Advertainment.

Segundo ele, apoiado em Gregório e Sung (2010), a Unilever, já no final do século XIX, planejava a inserção das suas marcas nos filmes da Lumiére, uma prática que ganhou corpo e se generalizou com o próprio crescimento da indústria cinematográfica. Ela se mantém até hoje, extrapolando para os games e outras novas possibilidades de interação com os consumidores, exigindo investimentos vultosos de anunciantes de peso. É importante registrar que, muitas vezes, dependendo do produto anunciado, a prática do product placement esteve envolvida em polêmica e desencadeou projetos de regulamentação, 
como ocorreu com a propaganda de cigarros (e do próprio hábito de fumar) que atingiu seu auge nos áureos tempos de Hollywood e mereceu restrição severa a partir do final do século XX.

Advertainment é o termo utilizado para designar a aproximação da publicidade (advertising) e do entretenimento a partir de produções audiovisuais, mas que, diferentemente das produções publicitárias tradicionais que têm como pressuposto fundamental a persuasão, busca dar visibilidade às marcas valendo-se do entretenimento. Na quase totalidade dos casos, o consumidor é estimulado (ou convidado) a contemplar a produção, que não lhe é imposta como na propaganda tradicional. A grande adesão dos cidadãos/consumidores às mídias sociais permite a inserção de vídeos com esse perfil, que serão clicados e compartilhados, o que Ihes confere significativa divulgação. Se elaborado e veiculado de forma criativa, o advertainment ardilosamente aparece diante do consumidor de forma natural, o que favorece o engajamento e a percepção positiva da marca nele inserida. As agências e os profissionais de propaganda, baseados em pesquisas e observações criteriosas, admitem que a credibilidade das estratégias de comunicação de marca pode ter um incremento quando o apelo para o consumo não é agressivo ou invasivo, mas sutilmente se desvanece em meio a uma mensagem ou conteúdo relevante, interessante e divertido.

Algumas destas práticas ou técnicas incorrem em alguns equívocos quando buscam viabilizar o processo de comunicação de marca, porque abrem mão da transparência (estão empenhadas em burlar a vigilância dos consumidores e dos stakeholders) para a consecução de um objetivo estritamente mercadológico. Com isso, elas incorrem em perda de legitimidade e eficácia, afetam negativamente a personalidade e a imagem da marca, seus atributos fundamentais. Neste artigo, analisamos a proposta de comunicação de marca do Grupo Odebrecht desenvolvida a partir do escândalo da Lava-Jato e que se apropria do brand content (em especial do jornalismo patrocinado) e da comunicação institucional.

\section{O branded content corporativo}

O branded content, expressão cunhada há menos tempo do que as demais anteriormente enunciadas, representa um passo adiante em termos de comunicação de marca porque incorpora novos elementos e novas táticas para prender a atenção do consumidor e conduzi-lo a uma prontidão indispensável para a realização de negócios.

O branded content costuma ser apresentado como sinônimo de marketing de conteúdo, mas há especialistas que divergem desta posição, com o argumento de que o branded content segue a abordagem típica da publicidade e pode 
ser considerado como a elaboração e a veiculação de um conteúdo, muitas vezes inserido em uma campanha (como na publicidade tradicional) para dar visibilidade a uma marca. Já o marketing de conteúdo tem como proposta a produção e veiculação contínua de conteúdo visando criar uma audiência cativa e que não se resume a campanhas que podem ser lançadas pontualmente ao longo do tempo.

Cássio Politi, diretor de uma das mais conceituadas agências de content marketing em nosso país, apoiado em Joe Pulizzi, do Content Marketing Institute, define marketing de conteúdo como: "'uma abordagem estratégica de marketing focada em criar e distribuir conteúdo valioso, relevante e consistente para atrair e reter um público-alvo claramente definido - e, em última análise, conduzi-los a ações rentáveis como consumidores" (Politi, 2017). Politi se empenha, insistentemente, em diferenciaromarketing de conteúdo de propaganda. Eleexplica:

O propósito de um programa de content marketing é criar uma relação longa da marca com o público, fortemente amparada no compartilhamento de conteúdo útil e relevante. Em suma, as empresas publicam em diversos canais aquilo que sabem, e não o que vendem. É uma relação, portanto, de longo prazo. Content marketing não se propõe a substituir a propaganda, que como um instrumento de comunicação se adapta aos formatos de mídia que surgem a todo momento. Portanto, content marketing e propaganda podem (e devem) perfeitamente coexistir. Enquanto o conteúdo útil e relevante visa a fomentar a audiência, a propaganda tem como finalidade converter essa audiência em oportunidades comerciais. (Politi, 2017)

Politi, ao fazer a distinção entre branded content e marketing de conteúdo, associa o primeiro à propaganda e o segundo ao jornalismo, mas há uma diferença abissal entre marketing de conteúdo e jornalismo, ainda que as duas atividades tenham como prática comum à produção de conteúdos. O jornalismo incorpora um sistema peculiar de produção, é desenvolvido por profissionais que têm um perfil definido, assume um discurso com determinadas características, e obedece a um código de ética que explicitamente o situa em antagonismo ao marketing. A confusão deriva do fato de muitos profissionais (e mesmo estudiosos) entenderem como sinônimas as expressões "marketing de conteúdo" e "jornalismo de marca", mas a prática do "jornalismo de marca" (e, portanto, do marketing do conteúdo) também não se caracteriza como jornalismo porque tem como intenção (ainda que nem sempre explicita ou transparentemente) "gerar ações rentáveis dos clientes ou consumidores". O jornalismo se reporta basicamente aos cidadãos e não os reduz, pelo menos 
num primeiro plano ou exclusivamente, a consumidores em sua acepção tradicional (compradores de produtos ou serviços).

Há diversas abordagens e mesmo definições de branded content, mas podemos adotar, simplificadamente, a seguinte:

O conteúdo de marca é qualquer forma de publicidade que use "conteúdo" - basicamente artigos, vídeos, infografia tanto em sites como em mídias sociais - para apoiar, apresentar ou promover produtos ou serviços. Difere de publicidade direta na medida em que não funciona principalmente como veículo para promoção de marca, mas sobretudo como um veículo de informação ou entretenimento que adicionalmente contribui para promover a marca.' (Market Track, s.d)

É possível admitir que o branded content também contempla a marca institucional ou corporativa e que algumas organizações o utilizam com esse objetivo. Ele integra, portanto, o mix contemporâneo de comunicação das empresas e tanto se reporta aos seus produtos e serviços como à marca institucional.

\section{Odebrecht: branded content ou ethicalwashing? ${ }^{2}$}

No caso específico da Odebrecht, objeto de nossa análise neste artigo, a marca foi construída durante décadas por ações permanentes de comunicação/ marketing que, além de ressaltarem a sua competência técnica nas diversas áreas de atuação (construção civil, engenharia, energia, química, petroquímica, saneamento e muitas outras), insistiam no compromisso do Grupo com a ética, a transparência, a sustentabilidade e o desenvolvimento nacional.

Este conjunto formidável de atributos positivos que foram, ao longo do tempo, incorporados à identidade e, em consequência, à imagem da marca Odebrecht sofreu abalo dramático a partir de 2015, no desenrolar da Operação Lava-Jato, que desvendou as relações espúrias entre o Grupo (e seus gestores, inclusive o patrono do grupo - Emílio Odebrecht e o seu presidente, Marcelo Odebrecht) e a classe política e governamental, de que resultou a prisão de quase

1 Trata-se da definição constante no portal da Market Track e que sintetiza, de forma adequada, as inúmeras definições encontradas na literatura e na web. A tradução acima é nossa e livre mas o texto original é: "Branded content is any form of advertising that uses "content" - typically articles, videos, infographics both on websites and social media - to support, represent or promote aproduct or service. It differs from straight advertising in that it doesn't openly function as a vehicle for brand promotion but rather as a vehicle for information or entertainment that also functions to promote the brand."

2 Cunhamos esta expressão para designar "limpeza ética", de forma muito semelhante a outra expressão largamente utilizada, o"greenwashing", que indica o esforço de uma empresa ou organização para "parecer verde" ou seja comprometida com o meio ambiente. 
70 diretores e do próprio presidente. Os depoimentos contidos nos vídeos que integram o processo de delação premiada destes executivos trouxeram à tona práticas criminosas desenvolvidas no Brasil e no exterior (propinas, suborno, apoio ilícito a campanhas eleitorais em troca de privilégios em concorrências etc) e degradaram a imagem e a reputação da companhia, associada aos níveis mais altos de corrupção empresarial. O confronto do discurso tradicional da Odebrecht, grandiloquente e autoelogioso, com a realidade das suas práticas descontruiu a sua marca e a sua credibilidade.

Mais de 100 mil funcionários perderam o emprego em apenas dois anos desde que a crise foi desencadeada e as ações da empresa sofreram abalo devastador.

Preocupada com as consequências desastrosas do escândalo, a empresa tomou uma série de providências (na verdade, foi obrigada a isso em nome da própria sobrevivência do Grupo que depende da continuidade dos contratos em andamento e da possibilidade de realizar novos contratos). Dentre estas, podemos destacar o acordo de leniência com a Controladora Geral da União, com o desembolso de pesada multa; e a revisão drástica da sua política de governança, de compliance associada à garantia dada pelo Grupo Odebrecht de que está agora comprometido com uma nova postura em termos de gestão e negócios.

Esse reposicionamento tem como suporte um amplo programa de comunicação que objetiva não apenas convencer a sociedade e o mercado de que a Odebrecht vai trilhar novos caminhos, mas também recuperar a autoestima interna, bastante abalada com a repercussão do episódio.

\section{Procedimentos metodológicos}

Como o objetivo deste artigo é exatamente analisar o esforço atual da Odebrecht para reposicionar a sua marca, com ações e discursos, que visam dissociá-la do escândalo da Lava-Jato e convencer a sociedade de que o Grupo se reinventou, a partir da adesão a um novo sistema de Governança Corporativa, buscamos reunir esses elementos. Evidentemente, os documentos e declarações que sustentam a nova posição da Odebrecht não estão consagrados em livros e ainda não foram objeto de dissertações ou teses e mesmo de artigos em periódicos científicos, mesmo porque a decisão da Odebrecht de investir nesse reforço de recuperação da imagem e reputação foi principalmente concretizada nos quatro primeiros meses do segundo semestre de 2017 (agosto a outubro). Recorremos, para esta análise, ao material publicado pela imprensa e sobretudo às publicações oficiais do Grupo (relatórios, vídeos institucionais etc.) constantes em seu portal ou peças de marketing de conteúdo inseridos na grande imprensa. 
Consultamos e analisamos 12 vídeos institucionais inseridos no Portal da Odebrecht, com atenção particular a quatro deles, intitulados: a) Respostas à sociedade (Odebrecht, 2017b); Como será a nova comunicação da Odebrecht (Odebrecht, 2017 d); A Odebrecht está preparada para virar a página? (Odebrecht, 2017 c) e O que vocês irão fazer para recuperar a reputação da empresa? (Odebrecht, 2017e). Embora existam outros vídeos institucionais no Portal, estes dizem respeito especificamente a ações ou estratégias de comunicação, foco deste artigo. Da mesma forma, recuperamos e analisamos documentos oficiais da empresa sobre a sua nova proposta administrativa, com destaque aos intitulados Compromisso com o Brasil (Odebrecht, 2016a ) e Política de conformidade (Odebrecht, 2016b), subsídios importantes para a "nova comunicação da empresa". Cotejamos este novo discurso com os que prevaleceu nos Relatórios Anuais dos anos de 2015 e 2016, no auge do processo de delação premiada e prisão dos gestores da Odebrecth, em especial o presidente Marcelo Odebrecht.

Para a análise do esforço de marketing de conteúdo desenvolvido pelo Grupo Odebrecht junto aos meios de comunicação, concentramo-nos nos jornais O Estado de S. Paulo, Folha de S. Paulo, O Globo e Valor Econômico e Meio \& Mensagem no período de julho a outubro de 2017.

Podemos agrupar as ações comunicacionais postas em prática pela Odebrecht, em quatro momentos, desencadeados em tempos distintos, mas estreitamente articulados: a) a elaboração e divulgação ampla de documento intitulado "Compromisso com o Brasil"; b) elaboração e divulgação da Política de Conformidade, com a explicitação de 10 compromissos assumidos pela nova gestão ; c) alteração da marca das empresas num processo que a Odebrecht denominou re-branding e d) divulgação interna e externa de suas posturas em relação ao mercado, à sociedade e aos seus trabalhadores, a partir de um conjunto de vídeos institucionais sobre vários temas; da presença agressiva nas mídias sociais com participação direta de seu gerente de comunicação, Marcelo Lyra; e do uso do marketing de conteúdo ou branded content em parceria com veículos da grande imprensa. Esta última ação comunicacional (branded content) foi analisada a partir de uma série de 10 peças, assinadas pela Braskem, empresa do Grupo, simulando reportagens, publicadas no jornal O Estado de S. Paulo, no período de agosto a outubro de 2017.

\section{Negação da gravidade e discurso de mudança}

Em todas estas ações, fica patente que o Grupo se recusa a admitir a gravidade de seus atos e que assume como estratégia reforçar a tese de que os problemas já foram superados, sem levar em conta o prejuízo que causou 
e continua causando ao país como se pretendesse descartar uma realidade incontestável: a Odebrecht continua ocupando papel de protagonista negativo na cobertura jornalística sobre a Operação Lava-Jato e faz parte da agenda permanente das sessões do STF, das reuniões da Procuradoria Geral da República e das operações que continuam sendo desenvolvidas pela Polícia Federal, além dos debates acalorados no Congresso Nacional.

No documento Compromisso com o Brasil, a Odebrecht afirma que "identificou a necessidade de implantar melhorias em suas práticas", como se as suas práticas delituosas requeressem apenas refinamento e não uma revisão integral, e explicita:

Ao contribuir com o aprimoramento do contexto institucional, a Odebrecht olha para si e procura evoluir, mirando o futuro. Entendemos nossa responsabilidade social e econômica, e iremos cumprir nossos contratos e manter os nossos investimentos. Assim, poderemos preservar os empregos diretos e indiretos que geramos e prosseguir no papel de agente econômico relevante, de forma responsável e sustentável. (Odebrecht, 2016a).

Num tom ao mesmo tempo otimista e descomprometido com a realidade, o documento fala em "preservar os empregos diretos e indiretos" quando, na verdade, não tem controle sobre essa questão, tanto que que foi responsável diretamente ou indiretamente pela perda de 100 mil empregos, como mencionado anteriormente.

A Política de Conformidade está expressa em um documento bastante detalhado, que inicia apresentando os conceitos de ética, transparência e integridade, descreve o sistema de conformidade, os princípios de governança, define os deveres e as responsabilidades dos líderes e dos demais integrantes da empresa e apresenta formas ideais de relacionamento com os diversos stakeholders.

É sintomático perceber, no texto do portal da Odebrecht sobre a Política de Conformidade que ela reconhece a importância da prevenção ("porque prevenir é sempre melhor e oneroso do que remediar") mas que prefere não tocar o dedo na ferida: as posturas inaceitáveis e moralmente nefastas da empresa, reveladas na Operação Lava-Jato, não foram praticadas generalizadamente pelos funcionários, mas sim pelos seus principais gestores, inclusive a presidência, o que é escamoteado pelo texto de apresentação da Política que, explicitamente, indica ao final: 
Para orientar o comportamento e as ações de todos os integrantes da Odebrecht, foi aprovada no final de 2016 a Política sobre Conformidade. É um documento robusto e amplo, com regras detalhadas sobre como os integrantes devem se comportar entre si e no relacionamento com Acionistas, Clientes, Fornecedores, Concorrentes, Governos, Comunidades e a sociedade em geral.

É uma proposta mais moderna e que responde às questões mais atuais da sociedade, com orientações sobre práticas anticorrupção, lavagem de dinheiro, conflitos de interesse, relacionamentos com fornecedores e acionistas, entre outros. São regras claras e objetivas para não deixar dúvidas na tomada de decisão pelo funcionário (grifo nosso) (Odebrecht, 2016 b).

A empresa resolveu também mudar os nomes e os logotipos das empresas pertencentes à sua holding com a exclusão da palavra Odebrecht, buscando apagar a marca que ficou indelevelmente associada à corrupção e práticas de negócios ilícitas. Na prática, o Grupo está contrariando uma decisão anterior, de 2013, protagonizada pelo seu presidente, Marcelo Odebrecht, preso pela Operação Lava Jato, que havia unificado a marca Odebrecht para suas empresas. Para justificar o fato, ela tentou convencer o mercado, a sociedade e seus públicos estratégicos de que as mudanças efetuadas "são condizentes com uma nova realidade na gestão das empresas, que ganharão maior autonomia em relação à holding" e que ela viabiliza "a busca de novos sócios e de modelagem de uma governança mais próxima de uma empresa de capital aberto em todos os negócios", conforme declaração do gerente de comunicação Marcelo Lyra. (Cunha, 2017). Pretendeu, portanto, desviar o foco, creditando a mudança dos nomes e logotipos das empresas a uma decisão meramente técnica, tentando caracterizá-lo como uma estratégia de re-branding. $O$ esforço não foi bem sucedido, como se pode depreender do posicionamento dos jornais que noticiaram o fato. O Globo, na edição de 08/08/2017, com o título "Empresas da Odebrecht podem trocar de nome", acrescentou antes do início do texto: "Após desgaste com Lava-Jato, grupo quer recuperar reputação e atrair sócios" e completou no lead da reportagem: "Em razão do forte desgaste de sua marca após a Operação Lava-Jato, a Odebrecht está implementando mudanças na estratégia de comunicação de seus negócios". Finalizou a matéria com a opinião de um consultor Luiz Marcatti:

A estratégia é sumir com as marcas que estão com a imagem negativa, e tentar colocar outra que aparecerá como limpa. Mas a empresa precisará provar muito na prática, pois o mercado sabe como foram conduzidos os negócios" (Neto, 2017); 
A Folha de S. Paulo, no dia 07/07/2017, também interpretou da mesma forma a estratégia adotada pelo Grupo e foi incisiva no lead da reportagem que a relatou:

As empresas pertencentes à holding da Odebrecht começaram a mudar seus nomes e seus logotipos a partir deste mês, como parte de uma estratégia que vem sendo desenhada desde meados do ano passado, na tentativa de se distanciarem de um título que ficou associado à Lava- Jato e à corrupção. (Cunha, 2017).

Mesmo o Meio \& Mensagem, publicação especializada na área de Comunicação/Marketing, não suavizou o tom ao noticiar a proposta de mudança dos nomes e dos logos das empresas do Grupo. Com o título contundente "Pela reputação perdida", deixou claro que a estratégia de re-branding não tinha como inspiração uma simples arquitetura de marca, mas um esforço para "limpar a reputação", ou seja, como indicado no artigo, uma ação "ethicalwashing".

Ao que parece, a tentativa deliberada de "limpeza da marca" teve início pela Braskem, empresa do Grupo que atua no ramo petroquímico, e que não traz o nome Odebrecht, portanto não será obrigada a mudar de nome, mas apenas redesenhar sua identidade visual. De agosto a outubro de 2017, em parceria com o jornal O Estado de S. Paulo, a Braskem veiculou textos, que levam a sua assinatura e são produzidos pelo Media Lab Estadão, abordando o tema sustentabilidade, com o objetivo de associar a sua atuação a um dos atributos mais valorizados na contemporaneidade. ${ }^{3}$

A estratégia de"marketing de conteúdo ou branded content", utilizada pela Braskem nesta parceria, é dar informações sobre tópicos incluídos na temática sustentabilidade (desperdício dos recursos naturais, mudança climática, crise hídrica, consumo consciente) que mascaram a verdadeira intenção: dar espaço para a empresa apresentar seus programas. A tentativa deliberada de destacar a Braskem é agressiva e demonstra a parcialidade da cobertura. Na pretensa reportagem do dia 29 de agosto (Braskem, 2017), o texto informa, ao final: "Empresas como a Braskem vêm trabalhando no desenvolvimento de produtos e soluções que contribuam com a reciclagem, o pós-consumo e o meio ambiente".

3 Esta parceria entre veículos e anunciantes é equivocadamente denominada de "jornalismo patrocinado" e tem merecido restrições por parte dos profissionais de imprensa comprometidos com a independência jornalística, porque afronta o próprio código de ética da categoria. Na verdade, como representa apenas um esforço para aumentar a receita dos veículos, esta alternativa tem uma inspiração meramente mercadológica, comercial, visto que o anunciante, no caso a Braskem, tem a palavra final sobre o texto a ser publicado. Esta condição torna a reportagem adjetivada, que explicitamente proclama as virtudes do anunciante, ainda que busque mascarar esta intenção pelo uso da técnica jornalística, inclusive com o uso de fontes não pertencentes à empresa. 
$\mathrm{Na}$ "reportagem" de 4 de setembro (Braskem, 2017), o texto fala no esforço das empresas em desenvolver produtos e soluções para minimizar os impactos das mudanças climáticas e cita apenas a contribuição da Braskem. Na "reportagem" de 19 de setembro (Braskem, 2017 ), o mesmo recurso é utilizado, com o texto indicando que "o desafio da redução de consumo é um tema que também faz parte das agendas de discussões de um número cada vez maior de empresas em todo o mundo" para, depois, complementar: “Entre elas, está a Braskem, que desde 2002 já investiu cerca de $\mathrm{R} \$ 280$ milhões em projetos para a melhoria da eficiência hídrica" e finalizar com declarações de um de seus executivos sobre o "compromisso sustentável da empresa".

$\mathrm{Na}$ verdade, o conceito de sustentabilidade que vigora nestes textos apresentados pela Braskem, e produzidos pelo Media Lab Estadão, tem um viés importante: em geral reportam-se à dimensão econômica da sustentabilidade porque, no fundo, a empresa enxerga este valor fundamental do mundo moderno como oportunidade para negócios e quase nada além disso.

Pode também parecer coincidência, mas não é: todos os 10 textos publicados com o patrocínio da Braskem, publicados e objeto de nossa análise, embora versem sobre um tema com grande tangência com a economia, o meio ambiente, os direitos humanos etc., aparecem no Caderno 2 de O Estado de $S$. Paulo, dedicado às variedades (cinema, teatro, televisão, colunas sociais etc.). Qualquer que seja a justificativa para essa inserção em um caderno não usual para esta temática não apaga a impressão de que a proposta era colocar a empresa em um espaço onde necessariamente ela não está presente, sobretudo neste momento em que o Grupo Odebrecht, e a Braskem em particular, são citados como protagonistas de um escândalo de proporção global, com o pagamento de propinas e outras posturas ilícitas, no Brasil e no exterior.

Essa estratégia da Odebrecht para "lavar a marca" não tem se limitado apenas ao público externo, mesmo porque as ações neste sentido têm sido também sistematicamente apresentadas aos seus funcionários. Há claramente um esforço significativo para levantar a autoestima dos "colaboradores", com a utilização de vídeos institucionais e a realização de reuniões gerenciais, que tem como clima a "nova Odebrecht, a "Odebrecht do futuro" O conjunto de 12 vídeos recém lançados pela empresa estão distribuídos em 4 grandes categorias, a saber: Esforço e superação, Nova postura, Perspectivas e Valores, e todos se enquadram em uma proposta denominada "Respostas à sociedade", como se a empresa estivesse respondendo a questionamentos dos seus stakeholders internos e externos. (Odebrecht, 2017 b) Eles têm como objetivo maior criar de um clima de otimismo, convocando os funcionários a contemplarem o futuro, como se a realidade dramática da empresa e do país, ainda contundente, já tivesse 
se transformado em uma "página virada". Aliás, este é o título de um dos vídeos: "A Odebrecht está preparada para virar a página?" (Odebrecht, 2017c). Alguns vídeos buscam mobilizar os funcionários para uma nova jornada, indicando que o"pior já passou" e que há boas "perspectivas de carreira para os atuais e futuros integrantes", quase sempre tentando atenuar as responsabilidades da empresa pela sua crise reputacional.

Há pelo menos dois vídeos que tratam diretamente da comunicação: "Como será a nova comunicação da Odebrecht" (Odebrecht, 2017d) e "O que vocês vão fazer para recuperar a reputação da empresa?" (Odebrecht, 2017e) e, em ambos, as declarações são genéricas, pouco esclarecedoras ou transparentes, com menção a ações que são habituais no mundo corporativo e que, necessariamente, não representam compromisso com a mudança de posturas, ainda que este seja o discurso vigente nestes e em todos os outros vídeos.

\section{Considerações finais}

Embora represente processo vital para as organizações modernas, a comunicação de marca não pode caracterizar-se apenas pela sua competência técnica, mas incorporar obrigatoriamente um vínculo indissociável entre a sua gestão (sua prática) e o seu discurso.

Numa sociedade conectada, em que a vigilância dos stakeholders e da opinião pública é acentuada, a dissonância entre as falas da organização e as suas posturas reais é identificada e denunciada de imediato.

Como consequência, a imagem e a reputação de uma organização costumam ser dramaticamente penalizadas, exigindo para sua recuperação um abrangente, longo e oneroso esforço comunicacional. Mesmo com a adoção de uma competente estratégia de comunicação, o discurso de empresas envolvidas em escândalos, como ocorreu com a Odebrecht, permanece sob suspeita por um tempo que pode ser mais ou menos longo, na dependência da avaliação dos públicos estratégicos e da sociedade. Essa suspeita só será efetivamente levantada quando estiver consolidada a percepção pública (e dos públicos) de que a empresa efetivamente começou a trilhar o caminho da ética e da transparência.

A Odebrecht, com a sua proposta de comunicação, pretende convencer o mercado e a sociedade de que já está em curso uma nova realidade e que ela não lançará mão no futuro das atitudes e posturas éticas e morais condenáveis que caracterizam a sua trajetória.

O que se percebe, de imediato, no entanto, é que a comunicação do Grupo, no momento seguinte ao acordo de leniência e ao anúncio de que a 
empresa mudou de atitude, encerra uma contradição: a Odebrecht apregoa que a companhia sempre teve a ética e a transparência como pilares de sua cultura, mas, como ficou patente com a Operação Lava-Jato, ela sempre as afrontou de maneira acintosa e esses valores só existiam efetivamente no discurso organizacional. Será mesmo difícil acreditar que, desta vez, esses valores serão respeitados, levando-se em conta que o "fiador" desta cultura, o seu patrono Emílio Odebrecht, teve papel destacado nas delações premiadas e permanece à frente do Grupo.

No Relatório Anual de 2015, referente às atividades da empresa no ano interior, exatamente quando se inicia a Operação Lava-Jato, a mensagem de Emílio Odebrecht, à época presidente do Conselho de Administração da empresa, pai de Marcelo Odebrecht, preso logo no início da Operação, escancarava a contradição entre o discurso e a prática da companhia. Dizia ele (Odebrecht , 2016c, p.11.):

Entendemos (...) que o problema da corrupção merece atenção, cuidados e combate extremos, e que se faz necessário evidenciar a licitude de quaisquer ações envolvendo recursos públicos. Acreditamos que as relações entre o setor público e o setor privado devem ser plenamente transparentes. Por isso concordamos que sejam facultadas ao exame da sociedade todas as transações entre empresas e órgãos do Estado. E consideramos fundamental a boa governança dos recursos públicos, para que sejam investidos de forma racional em iniciativas que melhorem a qualidade de vida da população e contribuam para o desenvolvimento do país (grifo nosso).

Este mesmo Relatório, em sua abertura, mantém o mesmo tom sobre a postura ética e moral da empresa:

\begin{abstract}
Mais de sete décadas de presença em diferentes mercados, regiões e países fazem da Organização Odebrecht um exemplo de solidez, com atuação pautada pela confiança nas pessoas e no espírito de servir. O crescimento dos Negócios está diretamente vinculado ao desenvolvimento de países e regiões. Os resultados obtidos são decorrentes da união de equipes em torno dos conceitos éticos e morais (grifo nosso), definidos na Tecnologia Empresarial Odebrecht (TEO) (Odebrecht , 2016c , p. 3.).
\end{abstract}

A Odebrecht promete que está olhando para o futuro, mas deverá transcorrer ainda um bom tempo para que ela se liberte do seu passado. Apesar do seu esforço e das boas intenções, a desconfiança ainda está presente na avaliação dos seus stakeholders e da sociedade e não será apenas a comunicação que conseguirá fazê-la superar este desafio. 
Como acentua o seu executivo de comunicação, Marcelo Lyra:

Temos de reconquistar o direito de ser ouvidos. A recuperação da reputação é algo de longo prazo, é uma trajetória. Precisamos ter uma história para contar. Passar a mensagem do dever de casa feito. A Odebrecht não é só corrupção. Sua qualidade em termos de capacidade técnica, inovação e pessoas é reconhecida. É essa a percepção que queremos transmitir". (Murad, 2017, p. 18)

Uma comunicação de marca, por mais competente que seja, não reverte sozinha situações tão desfavoráveis como o abalo reputacional de uma empresa. Será necessário verificar, no futuro, se "a percepção que a Odebrecht quer transmitir" foi validada pelos stakeholders a partir de suas novas posturas e atitudes. O prejuízo econômico e moral que o Grupo acarretou ao país foi incalculável, mas, assim como os criminosos, que ao cumprirem integralmente a pena pelos seus atos, resgatam a liberdade e a cidadania, a Odebrecht e sua comunicação merecem ter uma nova chance.

\section{REFERÊNCIAS}

BRASKEN. Consumo e produção responsável buscam reduzir impactos e desperdício. O Estado de S. Paulo. São Paulo. 29/08/2017. Caderno 2, p. C5.

BRASKEM. Unidos pelo planeta. O Estado de S. Paulo. São Paulo. 04/09/2017. Caderno 2, p. C3.

BRASKEM. Falta de chuva pede atenção para o consumo de água. O Estado de S. Paulo. São Paulo. 19/09/2017, Caderno 2, p. C3.

CUNHA, Joana. Odebrecht começa a mudar seus logotipos. Folha de S. Paulo. São Paulo. 07/08/2017, p. A20.

DE GREGORIO F.; SUNG, Y. Understanding attitudes toward and behaviors in response to product placement. Journal of Advertising, 39(1), p. 83-96, 2010. https://doi.org/10.2753/JOA0091-3367390106.

FREITAS, Flávia D' Albergaria; ALMEIDA, Victor Manoel Cunha de. Modelo teórico do engajamento no contexto das comunidades de marca. BRB. Brazilian Business Review. Vitória/ES. FUCAPE Business School. V. 14, n. 1, jan./fev., 2017, p. 87-109. Disponível em: http://www.scielo.br/pdf/bbr/v14n1/pt_1808-2386bbr-14-01-0086.pdf. Acesso em: 10 out. 2017.

FREITAS, Mariza Branco Rodrigues de;NETO, Manoel Marcondes Machado. Marca: do marketing ao balanço financeiro. Rio de Janeiro: Editora UERJ, 2015. 
MARKET TRACK. What is branded content? Disponível em: https://markettrack.com/ quick-answers/content/what-branded-content. Acesso em: 22 set. 2017.

MURAD, Fernando. Pela reputação perdida. Meio \& Mensagem. São Paulo, 07/08/2017, p. 18.

NETO, João Sorima. Empresas da Odebrecht podem trocar de nome. $\mathbf{O}$ Globo. Rio de Janeiro, 08/08/2017, p. 18.

ODEBRECHT. Compromisso com o Brasil. Disponível em: https://www.odebrecht. com/pt-br/comunicacao/releases/compromisso-com-o-brasil. 2016a. Acesso em: 10 set. 2017

Política de conformidade. Disponível em: https://www.odebrecht.com/ptbr/governanca/conformidade. 2016b. Acesso em: 22 set. 2017.

. Relatório Anual 2015. São Paulo. 2016c. Disponível em: https://www. odebrecht.com/sites/default/files/ra_odebrecht_2015.pdf. Acesso em: 21 set. 2017.

.Respostas à sociedade. São Paulo. 2017b. Disponível em: http://relatorioanual. odebrecht.com/videos_pt.html. Acesso em: 10 set. 2017.

A Odebrecht está preparada para virar a página? São Paulo, 2017c. Disponível em: http://relatorioanual.odebrecht.com/videos_pt_video11. html\#video11. Acesso em: 10 set. 2017.

Como será a nova comunicação da Odebrecht? São Paulo. 2017d. Disponível em: http://relatorioanual.odebrecht.com/videos_pt_video10.html\#video10. Acesso em: 10 set. 2017.

O que vocês irão fazer para recuperar a reputação da empresa? São Paulo, 2017e. Disponível em: http://relatorioanual.odebrecht.com/videos_pt_ video12.html\#video12. Acesso em: 10 set. 2017.

Relatório anual 2015. São Paulo. 2016 c. Disponível em: http://www. odebrecht.com/sites/default/files/ra_odebrecht_2015.pdf. Acesso em: 7 mar. 2017.

POLITI, Cássio. O que é content marketing? 2017. Disponível em: https://www.tracto. com.br/blog/o-que-e-content-marketing/. Acesso em: 22 set. 2017.

SERRALVO, Francisco Antoni. Gestão de marcas no contexto brasileiro. São Paulo: Saraiva, 2008.

TYBOUT, Alice M; CALKINS, Tim (org). Branding. São Paulo: Atlas, 2006.

TOMIYA, Eduardo. Gestão do valor da marca. 2. Ed., Rio de Janeiro: SENAC, 2010. 
TROIANO, Jaime. As marcas no divã. Rio de Janeiro: Editora Globo, 2009.

VIANA, Pablo Moreno Fernandes. Do Product Placement ao Branded Content: Uma revisão bibliográfica a partir da base de dados Scopus. In: XXXIX Congresso da Intercom. São Paulo: Intercom, 2016. Disponível em: http://portalintercom.org. br/anais/nacional2016/resumos/R11-1074-1.pdf. Acesso em: 20 set. 2017.

Recebido em: 4/10/2017

Aceito em: 23/1/2018

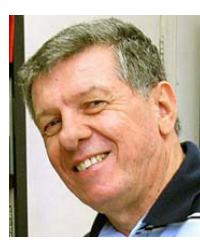

Dados do autor:

Wilson da Costa Bueno| wilson@comtexto.com.br

Universidade Metodista de São Paulo

Professor do Programa de Pós-Graduação em Comunicação Social da UMESP, jornalista, tem mestrado e doutorado em Comunicação (USP) e especialização em Comunicação Rural. Já orientou mais de uma centena de dissertações e teses em Comunicação/Jornalismo. Líder do grupo de pesquisa Criticom, cadastro no CNPq.

Programa de Pós-Graduação em Comunicação Social

Universidade Metodista do Estado de São Paulo

Endereço do autor:

Rua Alfeu Tavares, 149

09641-000 - São Bernardo do Campo (SP) - Brasi 